\title{
EL IMPACTO DEL COVID-19 EN LAS MUJERES tRabajadoras del Perú. ¿SE INCREMENTA LA DESIGUALDAD Y LA VIOLENCIA EN EL TRABAJO?
}

\author{
Evelin Coloma Cieza* \\ Universidad de Lima, Lima, Perú \\ Recibido: 1/1/2021 Aceptado: 20/1/2021 \\ doi: https://doi.org/10.26439/iusetpraxis2021.n053.5064
}

\begin{abstract}
RESUMEN. La pandemia ocasionada por el virus SARS-CoV-2, que causa el COVID-19, viene afectando gravemente a diversos países en el mundo como resultado de la crisis sanitaria, social y económica generada. El Perú no ha sido ajeno a esta situación; por un lado, el número de víctimas de la enfermedad continúa incrementándose día a día y, por el otro, nuestra economía atraviesa una crisis como consecuencia de las medidas de restricción decretadas por el Gobierno para frenar la propagación de los contagios, que implicaron la paralización de diferentes actividades económicas. Esto ha impactado en los hogares y las empresas, pues en los últimos meses se han perdido más de tres millones de empleos, lo cual agrava el alto índice de informalidad que existe en nuestro país, y ha afectado en mayor medida a las mujeres trabajadoras. Esta situación podría profundizar las desigualdades preexistentes, así como los casos de violencia de género en el ámbito laboral.
\end{abstract}

PALABRAS CLAVE: mujeres trabajadoras / desigualdad salarial / violencia en el trabajo / hostigamiento sexual / acoso laboral

\footnotetext{
* Abogada por la Universidad de Lima, Perú. Máster en Consultoría Jurídico-Laboral por la Universidad Carlos III de Madrid, España. Profesora de la Facultad de Derecho de la Universidad de Lima. Directora del Área de Derecho Laboral y Migratoria del Estudio Llona \& Bustamante Abogados.
} 


\title{
THE IMPACT OF COVID-19 ON WORKING WOMEN IN PERU. IS INEQUITY, WORKPLACE VIOLENCE AND HARASSMENT INCREASING?
}

\begin{abstract}
The SARS-CoV-2 (COVID-19) pandemic severely affects many countries due to the health, social, and economic crises it generates. Peru is one of the countries affected by this situation. The number of victims of the virus in the country keeps going up every day, and our economy is going through a crisis due to restrictions put in place by the government to stop the spreading of the virus. These measures halted several economic activities, which, in turn, affected both businesses and households. More than three million jobs have been lost in the last few months, which increases the high rate of informal economic activities already performed in our country. This has disproportionally affected working women, a situation which could widen the existing gender gap as well as increase the cases of violence against women in the workplace.
\end{abstract}

KEYWORDS: working women / gender pay gap / workplace violence / sexual harassment / mobbing 


\section{INTRODUCCIÓN ${ }^{1}$}

Como recordamos, el 11 de marzo del 2020 se declaró el estado de emergencia sanitaria y, posteriormente, se decretó el estado de emergencia nacional con aislamiento social obligatorio, medidas que se ejecutaron a partir del 16 de marzo del 2020. La adopción de estas disposiciones significó que solo determinadas actividades económicas, consideradas esenciales, pudieran continuar operando de forma presencial. Asimismo, como mecanismo de protección, se dispuso que aquellos trabajadores que pertenecían a la población de riesgo frente al COVID-19 realicen labor a distancia, bajo la figura del trabajo remoto, correspondiéndoles el pago de una licencia con goce de haber compensable cuando este no resultara aplicable.

En ese contexto, la situación más difícil la enfrentaron las actividades calificadas como no esenciales, pues hasta la regulación de las fases para la reactivación de diversos sectores de la economía solo estaban autorizadas a realizar labor remota, lo cual era una limitación considerable a sus operaciones. Esta paralización súbita afectó -y todavía lo hace-considerablemente a los empresarios de estos sectores, que vieron reducidos notablemente sus ingresos. Como consecuencia, en muchos casos, fue necesario el cierre definitivo de los centros de trabajo, situación que impacta indudablemente en un importante número de hogares en nuestro país.

El Perú se encuentra atravesando una grave crisis que alcanza a diversos ámbitos, como la salud, la economía y el empleo. En ese sentido, resulta importante evaluar cómo esta crisis afecta a las mujeres trabajadoras en el Perú, población que antes del inicio de la cuarentena ya presentaba menores tasas de ocupación; un alarmante número de empleo a tiempo parcial, temporal o a plazo fijo; desempeño de labores en pequeñas empresas, bajo condiciones de informalidad y de subempleo; o de forma autónoma, así como una mayor carga de labor no remunerada en sus hogares.

Cabe precisar que, según la Organización Internacional del Trabajo (OIT, 2020b), a diferencia de otras crisis económicas que afectaron en gran medida el empleo masculino, la crisis ocasionada por el COVID-19 ha impactado en la reducción del empleo y jornadas laborales de las mujeres, que trabajan en mayor proporción que la población masculina en los sectores sobreexpuestos por la pandemia, es decir, aquellos con mayor riesgo de reducción de la jornada de trabajo, recortes salariales y despidos, como los servicios de alojamiento, alimentación, comercio, producción (fábricas), entre otros.

En el presente artículo abordaremos, en primer lugar, el presupuesto base para determinar la idoneidad de las condiciones de trabajo en el concepto acuñado por la

1 La presente investigación contó con la colaboración del estudiante de la Facultad de Derecho de la Universidad de Lima y asistente legal del Estudio Llona \& Bustamante Abogados, Luis Felipe Chipana Aguilar. 
OIT como el trabajo decente. Luego, expondremos algunas de las manifestaciones de la discriminación y violencia en el ámbito de las relaciones laborales. Finalmente, evaluaremos si dichas formas de discriminación y violencia se han incrementado en el marco de la pandemia del COVID-19 afectando desigualmente a las mujeres trabajadoras.

\section{EL TRABAJO DECENTE COMO PARÁMETRO PARA EL RESPETO DE LOS DERECHOS FUNDAMENTALES DE LAS TRABAJADORAS}

El derecho al trabajo se encuentra reconocido en diferentes instrumentos internacionales como la Declaración Universal de los Derechos Humanos, la Declaración Americana de los Derechos y Deberes del Hombre, el Pacto Internacional de Derechos Civiles y Políticos, la Convención Americana sobre Derechos Humanos, entre otros. Este derecho constituye no solo un fenómeno jurídico, sino también un hecho económico y social que influye intrínsecamente en la dimensión íntima, personal y familiar del trabajador, y subsecuentemente en la esfera económica y productiva del empleador.

El trabajo es un medio de realización que permite el sostenimiento del trabajador y de su familia. Por tal razón, no solo consiste en el derecho a obtener un puesto para laborar, sino también a conservarlo, a desarrollarlo en condiciones adecuadas y a recibir una remuneración equitativa y justa. Dicha connotación supone que el derecho al trabajo se encuentre connaturalmente vinculado al ejercicio de otros derechos que han sido reconocidos como fundamentales en la Constitución Política del Perú de 1993, como, por ejemplo, el derecho a la dignidad, a la vida, a la integridad moral, psíquica y física, a la igualdad y a la no discriminación.

Así, el empleador se encuentra constreñido a cumplir con las normas que integran el sistema jurídico peruano, conformado por normas jurídicas de producción nacional, así como por aquellas que han sido incorporadas mediante la ratificación de tratados y convenios de las organizaciones internacionales, como la Organización de las Naciones Unidas (ONU) y la OIT, entre otras, conforme a lo establecido en los artículos 55, 56 y 57 de la Constitución.

En ese sentido, nos remitimos a la Declaración Universal de los Derechos Humanos que, si bien no es un instrumento jurídico vinculante, constituye un importante marco de referencia en el reconocimiento de la concepción del valor supremo del ser humano como titular de derechos inherentes e inalienables a su ser, hoy en día reconocidos como derechos fundamentales. Este reconocimiento determina que los seres humanos nacen libres e iguales en dignidad y en derechos; asimismo, que toda persona tiene los mismos derechos sin discriminación de raza, sexo, color, religión o cualquier otra condición.

Siguiendo lo antes expuesto, el Pacto Internacional de Derechos Civiles y Políticos, aprobado por la Asamblea General de las Naciones Unidas el 16 de diciembre de 1966 , 
reconoce el derecho a la igualdad ante la ley y a la no discriminación como inherente a la persona humana. Por tanto, prohíbe:

[...] toda discriminación y garantizará a todas las personas protección igual y efectiva contra cualquier discriminación por motivos de raza, color, sexo, idioma, religión, opiniones políticas o de cualquier índole, origen nacional o social, posición económica, nacimiento o cualquier otra condición social. (Artículo 26)

De otro lado, el Pacto Internacional de Derechos Económicos, Sociales y Culturales (1966) regula expresamente en el inciso a), literal i), de su artículo 7 "el derecho de todas las personas al goce de condiciones de trabajo equitativas y satisfactorias que garantizan, especialmente, los salarios equitativos e iguales por trabajo de igual valor, sin distinciones de ninguna especie".

Estas condiciones buscan, entre otros aspectos, asegurar que las personas y, como tales las mujeres, no reciban un trato diferente o condiciones inferiores por razón de su género en el desarrollo de su actividad laboral; procura erradicar los sesgos ocasionados por los estereotipos históricos que atribuyen determinados roles a las mujeres, e implementar nuevos mecanismos de evaluación basados en criterios objetivos.

Los derechos antes descritos confluyen en la necesidad de establecer como base de las relaciones laborales lo que la OIT denomina el derecho al trabajo decente. Este es concebido como oportunidades para que hombres y mujeres tengan un empleo decente y productivo; derecho a laborar en condiciones adecuadas de libertad, equidad, dignidad y seguridad humana; a la protección social para sus familias, mejores perspectivas de desarrollo personal e integración social, que se les garantice un salario adecuado (justo y equitativo), así como el cumplimiento de las normas sobre seguridad en el lugar de trabajo, igualdad de oportunidades y de trato, con el fin de mejorar el desarrollo productivo de la empresa y la vida personal de los trabajadores, con objetivos profesionales razonables y el respeto de sus derechos como personas y trabajadores. "Como podemos apreciar, el trabajo decente no solo contribuye al crecimiento económico y aumenta las oportunidades de trabajo, sino que aumenta y mejora la productividad de los trabajadores, y el desarrollo empresarial" (Coloma Cieza, 2012, p. 17).

En ese contexto, la OIT, en el marco del Programa de Trabajo Decente, ha diseñado una agenda con la finalidad de que la comunidad del trabajo, representada por sus mandantes tripartitos, movilice sus recursos. Para ello, dicha organización ofrece apoyo a través de programas nacionales de trabajo decente desarrollados en colaboración con sus mandantes, considerando cuatro objetivos estratégicos:

- Promover y cumplir las normas y los principios y derechos fundamentales en el trabajo.

- Crear mayores oportunidades para que mujeres y hombres puedan tener empleos e ingresos dignos. 
- Mejorar la cobertura y la eficacia de una seguridad social para todos.

- Fortalecer el tripartismo y el diálogo social.

Finalmente, cabe precisar que la Agenda 2030 de Desarrollo Sostenible ${ }^{2}$ reconoce la importancia del trabajo decente, considerándolo como motor del desarrollo sostenible que coloca en el centro a las personas. Esto se pone de manifiesto en su objetivo 8 , cuya finalidad es "promover el crecimiento económico sostenido, inclusivo y sostenible, el empleo pleno y productivo y el trabajo decente para para todos" (OIT, 2017).

\section{EL DERECHO A LA IGUALDAD DE OPORTUNIDADES DE LAS MUJERES TRABAJADORAS}

El derecho a la igualdad supera su concepción abstracta a través de su dimensión dinámica mediante el concepto de la igualdad de oportunidades, en la medida en que este último permite establecer condiciones concretas en las relaciones laborales, no en el sentido estricto y llano de una mera equiparación, sino en cuanto a permitir que las personas tengan las mismas condiciones en la realidad para materializar sus derechos en el marco de una relación de trabajo. Esto contribuye a que el Estado, como garante de este principio, identifique las situaciones que impiden que las personas compitan en igualdad de condiciones, a fin de establecer políticas de promoción de la equidad (entendida no como una igualdad aritmética, sino como una basada en términos de justicia, objetividad y razonabilidad), así como de proscripción de todo acto que contravenga la misma.

\section{Regulación supranacional: OIT}

La OIT ha establecido diversos mecanismos normativos sobre la igualdad que aportan herramientas para eliminar la discriminación en todos los aspectos relacionados con las relaciones de trabajo y con la sociedad, en general. Asimismo, estos instrumentos proporcionan las bases sobre las cuales deben aplicarse las estrategias de integración en materia de género en el ámbito de las relaciones laborales.

En ese contexto, el Perú, como parte de la OIT, ha suscrito convenios referidos a la igualdad de oportunidades, orientados a proteger y prevenir afectaciones a los derechos fundamentales de los trabajadores, como el Convenio 100, sobre igualdad de remuneración $(1951)^{3}$, que señala en el artículo 2:

2 La Agenda 2030 abarca las tres dimensiones de la sostenibilidad: económica, social y medioambiental. Está constituida por 17 Objetivos de Desarrollo Sostenible (ODS) que se basan en los progresos alcanzados a través de los Objetivos de Desarrollo del Milenio (ODM). Esta agenda fue adoptada por los líderes del mundo reunidos en una cumbre especial de las Naciones Unidas el 25 y 26 de septiembre del 2015 en Nueva York.

3 Ratificado por el Perú por la Resolución Legislativa 13284 de fecha 9 de diciembre de 1959. 
Todo Miembro deberá, empleando medios adaptados a los métodos vigentes de fijación de tasas de remuneración, promover y, en la medida en que sea compatible con dichos métodos, garantizar la aplicación a todos los trabajadores del principio de igualdad de remuneración entre la mano de obra masculina y la mano de obra femenina por un trabajo de igual valor.

Asimismo, el Perú ha ratificado el Convenio 111, sobre la discriminación (empleo y ocupación) (1958) ${ }^{4}$ de la OIT, instrumento que busca que los Estados miembros se obliguen a formular y llevar a cabo una política nacional que promueva, por métodos adecuados a las condiciones y a las prácticas nacionales, la igualdad de oportunidades, teniendo en cuenta principios como la igualdad, la libertad y la dignidad, entre otros; y de esta manera proscribir toda conducta que afecte a estos principios, como exclusiones o preferencias realizadas por motivos como el sexo y el género, que afecten la equidad de trato en el empleo.

\section{Regulación nacional}

El artículo 2, inciso 2, de la Constitución reconoce el derecho fundamental de toda persona a la igualdad ante la ley. Por su parte, el artículo 26 de la Carta Magna establece como uno de los principios que regulan la relación laboral la igualdad de oportunidades sin discriminación; y el artículo 24 regula el derecho de todo trabajador (sea hombre o mujer) a una remuneración equitativa y suficiente que procure para él y su familia el bienestar material y espiritual.

A fin de cumplir con el mandato constitucional, y como expresión de las políticas para lograr estándares compatibles con el trabajo prescrito por la OIT, a lo largo de los últimos años en el Perú se han venido implementando diversas normas y medidas orientadas a erradicar la brecha salarial y la desigualdad de oportunidades laborales que existen entre hombres y mujeres.

En ese contexto, con el objeto de lograr empleos justos, se han promulgado diversas leyes como la Ley 26772 , "Ley que dispone que las ofertas de empleo y acceso a medios de formación educativa no puedan contener requisitos que constituyan discriminación, anulación o alteración de igualdad de oportunidades", del 17 de abril de 1997; la Ley 28983, Ley de Igualdad de Oportunidades entre Mujeres y Hombres, del 16 de marzo del 2007, la cual busca establecer un marco normativo, institucional y de políticas públicas a fin de garantizar y proteger el ejercicio de los derechos de igualdad y dignidad entre hombres y mujeres no solo en el ámbito laboral, sino también en el social. La indicada norma atribuye un rol equitativo a todos los ciudadanos, sin importar el género, a fin de consolidar un sistema democrático.

4 Ratificado por el Decreto Ley 17687 de fecha 6 de junio de 1979. 
Posteriormente, se promulgó la Ley 30364, "Ley para prevenir, sancionar y erradicar la violencia contra las mujeres y los integrantes del grupo familiar", cuyo texto único ordenado ha sido aprobado por el Decreto Supremo 004-2020-MIMP el 4 de septiembre del 2020. Esta normativa, entre otras disposiciones, regula cuatro nuevos derechos laborales: (i) a no sufrir despido por causas relacionadas con dichos actos de violencia, (ii) al cambio de lugar u horario de trabajo en tanto sea posible y sin menoscabo de sus derechos remunerativos y de categoría, (iii) a la justificación de las inasistencias y tardanzas al centro de trabajo derivadas de dichos actos de violencia, y (iv) a la suspensión de la relación laboral, hasta por cinco meses (sin goce de remuneraciones), a pedido del trabajador o trabajadora víctima de violencia familiar, cuando esta haya sido autorizada por un juez.

Igualmente, la indicada norma establece que serán considerados como violencia contra las mujeres y los integrantes del grupo familiar la violencia física, psicológica y sexual, así como la violencia económica o patrimonial. Con relación a esta última, entre sus diferentes manifestaciones, se prescribe que la violencia económica se puede presentar en el ámbito laboral cuando se percibe un salario menor por igual tarea dentro de un mismo lugar de trabajo.

Finalmente, se promulgó la Ley 30709, "Ley que prohíbe la discriminación remunerativa entre varones y mujeres", el 26 de diciembre del 2017. Si bien esta norma tiene como objetivo principal garantizar el derecho de los trabajadores a percibir igual remuneración por igual labor, siguiendo los lineamientos de la Ley 28983, su alcance no se limita a tratar la igualdad remunerativa, sino que regula otras disposiciones que deberán observar los empleadores, tales como las siguientes:

- Garantizar a los trabajadores un trato digno, un clima laboral basado en el respeto y la no discriminación, así como la compatibilidad de vida personal, familiar y laboral.

- Asegurar que en los planes de formación profesional y de desarrollo de capacidades laborales de sus trabajadores se garantice la igualdad entre mujeres y hombres.

- Prohibición del despido y la no renovación de contrato por motivos vinculados con la condición de embarazo o el periodo de lactancia.

- Nuevas conductas calificadas como hostilidad laboral, agregando al inciso b) del artículo 30 del TUO del Decreto Legislativo 728, Ley de Productividad y Competitividad Laboral (LPCL), la reducción de la categoría y de la remuneración, además del incumplimiento de requisitos objetivos para el ascenso del trabajador, como un acto de hostilidad. Cabe indicar que la hostilidad laboral es una condición que configura un despido indirecto, que habilita al trabajador 
a solicitar el cese de dichos actos y, en su defecto, la indemnización por despido arbitrario.

Con relación a la obligación de garantizar la compatibilidad de vida personal, familiar y laboral, el Perú ha ratificado el Convenio OIT 156, sobre los trabajadores con responsabilidades familiares ${ }^{5}$, el cual indica que, con miras a crear la igualdad efectiva de oportunidades y de trato entre trabajadores y trabajadoras, se deberá incluir entre los objetivos de la política nacional el de permitir que las personas con responsabilidades familiares que desempeñen o deseen desempeñar un empleo ejerzan su derecho a hacerlo sin ser objeto de discriminación y, en la medida de lo posible, sin conflicto entre sus responsabilidades familiares y profesionales. Para dar cumplimiento a este mandato y reconociendo la necesidad de mejorar la condición de dichos trabajadores dentro de las medidas adoptadas por el Perú, se publicó la "Guía de buenas prácticas en materia de conciliación del trabajo y la vida familiar y personal", contenida en la Resolución Ministerial 048-2014-TR del 26 de marzo del 2014, mediante la cual se busca promover el cumplimiento de la normativa sobre igualdad de oportunidades, así como la prevención y erradicación de la discriminación sobre la base del género.

La norma busca concientizar a los ciudadanos y empleadores sobre uno de los posibles y quizá el más marcado origen de este tipo de segregación: la incorrecta redistribución de las responsabilidades familiares que recaen, generalmente, en las madres trabajadoras. Otro grave problema es aquel que radica en la errada conceptualización de los empleadores sobre la baja productividad que podrían tener, como resultado de la maternidad, las trabajadoras.

Dicho documento también recomienda medidas para mejorar el clima laboral y ayudar a extinguir la discriminación por género, tales como las vinculadas al tiempo y lugar de trabajo, al uso de herramientas virtuales o tecnologías de la información, y al apoyo con las responsabilidades familiares como brindar información sobre centros de formación y de cuidado de los hijos.

En ese orden de ideas, a fin de erradicar el estereotipo de que solo a las trabajadoras se les atribuye las responsabilidades familiares, estos mecanismos deben ser implementados, planificados y monitoreados de manera adecuada y a favor de trabajadores y trabajadoras.

\section{El derecho a la igualdad, contraste con la realidad}

Si bien en el ámbito normativo se han hecho esfuerzos para cautelar el derecho a la no discriminación, es notable que la realidad aún dista mucho de permitirnos afirmar que

$5 \quad$ Adoptado por el Perú a través de la Ley 24508 el 16 de abril de 1986. 
en nuestro país se ha erradicado la desigualdad que existe entre hombres y mujeres trabajadores, pues las brechas salariales se mantienen vigentes, así como la falta de equidad en el acceso al empleo, la promoción de mejores condiciones laborales y el mantenimiento de la fuente de trabajo.

\section{Desigualdad salarial entre hombres y mujeres}

La desigualdad salarial afecta de diversas formas. En la esfera individual del trabajador, vulnera el derecho de toda persona a ejercer un trabajo por el cual perciba un salario justo y equitativo; mientras que, en el aspecto económico, afecta la productividad del empleador y el crecimiento de su empresa, pues, al no evaluar con criterios objetivos, limita el potencial de sus trabajadoras e impide aprovechar sus aportes al desarrollo de la producción.

Este fenómeno es un problema persistente que se presenta a escala global; sin embargo, varía según los países o regiones que se analicen. Así, en el mercado laboral peruano, es usual encontrarnos frente a actos de discriminación por razones de género que se manifiestan, entre otros aspectos, en el pago de las remuneraciones 0 en las oportunidades para la promoción del empleo en igualdad de condiciones. En cuanto a la brecha salarial, es decir, la diferencia remunerativa entre hombres y mujeres, los datos estadísticos revelan una situación preocupante.

De acuerdo con la "Guía para la igualdad. 1. Igualdad salarial", aprobada por la Resolución Ministerial 243-2018-TR, a nivel nacional la brecha de ingresos entre hombres y mujeres en el año 2017 fue de 29 \%, lo que significa que el promedio agregado nacional de los ingresos de los varones fue de 1566 soles y el de las mujeres de 1107 soles. El mismo documento nos muestra que en el sector privado la brecha salarial entre hombres y mujeres es de $23,8 \%$, mientras que en el sector público es de $16 \%$. Como se puede apreciar, a pesar de que nuestra legislación estipula disposiciones orientadas a erradicar la brecha salarial, según el informe realizado por el Instituto Nacional de Estadística e Informática (INEI) el 7 de marzo del 2019, la brecha entre hombres y mujeres asciende a 572 soles. De las cifras detalladas, se desprende que, a pesar de que el género de una persona no es un indicador de capacidades, aptitudes ni competencias para realizar labores de igual valor, las mujeres siguen percibiendo menor remuneración que los hombres.

\section{VIOLENCIA EN EL TRABAJO}

Como hemos señalado, el trabajador, como ser humano, es titular de derechos fundamentales, tales como el derecho a la dignidad, a la vida, a la integridad, entre otros, los cuales no pueden ser afectados durante el desarrollo de su vida laboral. 
Sobre el particular, el Convenio 111 de la OIT, antes citado, establece con carácter absoluto la prohibición de la discriminación en el trabajo y, por tanto, no cabe ningún supuesto en el que se pueda tolerar o permitir que esta se materialice, pues forma parte del núcleo indisponible de derechos del trabajador (ius cogens laboral). A tales efectos, define así la discriminación:

(a) cualquier distinción, exclusión o preferencia basada en motivos de raza, color, sexo, religión, opinión política, ascendencia nacional u origen social que tenga por efecto anular o alterar la igualdad de oportunidades o de trato en el empleo y la ocupación;

(b) cualquier otra distinción, exclusión o preferencia que tenga por efecto anular o alterar la igualdad de oportunidades o de trato en el empleo u ocupación [...]. (Convenio 111, sobre la discriminación (empleo y ocupación), 1958)

Debido a su importancia, la prohibición de la discriminación ha sido reconocida en diversos instrumentos internacionales como la Declaración Universal de los Derechos Humanos, el Protocolo de San Salvador, la Declaración de la OIT de 1998, la Convención sobre la Eliminación de Todas las Formas de Discriminación contra la Mujer (CEDAW) ${ }^{6}$, la Convención de Belém do Pará de 19447 , entre otros.

En el Perú, la Ley 28983, que sirve de antecedente y marco para la Ley 30709 , establece el concepto de discriminación y los principios de un ordenamiento que la combata, definiéndola de esta manera:

Cualquier tipo de distinción, exclusión o restricción, basada en el sexo, que tenga por objeto o por resultado menoscabar o anular el reconocimiento, goce o ejercicio de los derechos de las personas, independientemente de su estado civil, sobre la base de la igualdad entre la mujer y el hombre, de los derechos humanos y las libertades fundamentales en las esferas política, económica, social, cultural o en cualquier otra, en concordancia con lo establecido en la Constitución y en los instrumentos internacionales ratificados por el Perú.

No podemos dejar de mencionar que el artículo 23 de la Constitución Política del Perú señala que "ninguna relación laboral puede limitar el ejercicio de los derechos constitucionales, ni desconocer o rebajar la dignidad del trabajador".

Dada la trascendencia de los derechos mencionados, su afectación constituye un acto de violencia, más aún si esta no solo se ejerce en el ámbito de una relación individual de trabajo, sino que obedece a patrones y estructuras de nuestra sociedad. Desde esa perspectiva, el literal h) del artículo 24 de la Constitución establece: “Nadie debe ser

6 Ratificada por el Perú por la Resolución Legislativa 23432 del 5 de junio de 1982.

7 Aprobada por la Resolución Legislativa 26583 del 22 de marzo de 1996. Fue ratificada el 4 de abril de 1996 y depositada el 4 de junio de 1996. Vigente desde el 4 de julio de 1996. 
víctima de violencia moral, psíquica o física, ni sometido a tortura o a tratos inhumanos o humillantes. [...]".

En ese contexto, la legislación laboral, dentro de las diversas manifestaciones de transgresión de los derechos del trabajador, regula en el artículo 30 de la LPCL a aquellas conductas prohibidas en las que puede incurrir el empleador, que han sido calificadas como actos de hostilidad, algunas de las cuales constituyen actos discriminatorios que implican violencia contra el trabajador:

Artículo 30.- Son actos de hostilidad equiparables al despido los siguientes: [...]

e) El acto de violencia o el faltamiento grave de palabra en agravio del trabajador o de su familia;

f) Los actos de discriminación por razón de sexo, raza, religión, opinión, idioma, discapacidad o de cualquier otra índole;

g) Los actos contra la moral y todos aquellos que afecten la dignidad del trabajador. [...].

Cabe precisar que en el marco de una relación laboral los trabajadores no solo se encuentran protegidos frente a los actos de violencia cometidos por el empleador o sus representantes, sino también frente a toda forma de violencia que pueda ser ejercida por otros trabajadores, independientemente de su ubicación y la de la víctima en la estructura jerárquica de la organización. La protección también alcanza a los prestadores de servicios y a los trabajadores contratados de forma indirecta por medio de la tercerización o intermediación laboral, y a los beneficiarios de las modalidades formativas.

Existen diferentes manifestaciones de violencia en el trabajo, entre las que se encuentra el acoso laboral, moral o psicológico, conocido con el término inglés mobbing, entendido como un conjunto de comportamientos por el cual una persona o grupo de personas ejercen violencia psicológica de forma sistemática y prolongada en el tiempo sobre otra persona en el lugar de trabajo. Esta forma de violencia se manifiesta por un trato o comunicación hostil y desprovista de ética, sobre la base de acciones cometidas por uno o varios individuos, principalmente contra un único trabajador, actos que son generalmente ejecutados de manera sutil, disimulada o indirecta. El mobbing afecta gravemente el derecho a la dignidad del trabajador, derecho inherente al ser humano, que se sustenta en el hecho de que la persona es un fin en sí misma, por lo que todo acto contrario a esta se encuentra prohibido y constituirá una infracción constitucional.

Otra manifestación de la violencia contra el trabajador es el hostigamiento sexual, cuyas consecuencias son graves y diversas no solo para los trabajadores, sino también para la sociedad en su conjunto. Por ello, la OIT (2008) establece:

El acoso sexual es considerado como una violación de los derechos humanos, una forma de discriminación y una cuestión de seguridad y salud. Es ofensivo para la 
dignidad y la integridad personal de los trabajadores de uno y otro sexo, y pone en entredicho su integridad personal y su bienestar. Socava también su derecho a la igualdad de oportunidades y de trato. Ha de prevenirse en el lugar de trabajo, $y$, cuando ocurra pese a todos los esfuerzos, debe ser castigado y sus víctimas protegidas. Con frecuencia, las víctimas desconocen sus derechos y temen a las represalias o la pérdida del puesto de trabajo; por ello, la concienciación es un elemento importante de la lucha contra este mal. (p. 22)

En nuestro ordenamiento, el hostigamiento sexual ha sido proscrito a través de la Ley de Prevención y Sanción frente al Hostigamiento Sexual (LPSHS), que tiene como objetivo erradicar toda forma de manifestación de estas conductas en las relaciones de autoridad o dependencia, cualquiera que sea la forma jurídica de esta relación, así como cuando se presente entre personas con prescindencia de jerarquía, estamento, grado, cargo, función, nivel remunerativo o análogo. En ese sentido, el artículo 4 de la LPSHS define que el hostigamiento sexual es:

[...] una forma de violencia que se configura a través de una conducta de naturaleza o connotación sexual o sexista no deseada por la persona contra la que se dirige, que puede crear un ambiente intimidatorio, hostil o humillante; o que puede afectar su actividad o situación laboral, docente, formativa o de cualquier otra índole.

Además, precisa que para que se configure este tipo de violencia no se requiere acreditar el rechazo ni la reiteración de la conducta.

Sobre las conductas que calificarían como hostigamiento sexual, el artículo 6 de la LPSHS plantea un listado abierto, que estaría en condiciones de adaptarse a las nuevas formas de hostigamiento que se podrían presentar de acuerdo con la evolución social y tecnológica.

Con relación al ámbito subjetivo de protección frente al hostigamiento sexual en el marco de las relaciones laborales, este alcanza al trabajador y a cualquier prestador de servicios sin importar la modalidad o forma contractual, así como a los beneficiarios de las modalidades formativas; y, en el ámbito objetivo, el hostigamiento sexual se configura independientemente de si existen grados de jerarquía entre la persona hostigada y la hostigadora, o si el acto de hostigamiento sexual se produce o no en el lugar o ambientes educativos, formativos, de trabajo o similares; o si este ocurre durante o fuera de la realización de dichas jornadas.

La protección frente a estos actos se materializa en obligaciones concretas para el empleador, tales como estas:

- Ofrecer capacitación y sensibilización en materia de hostigamiento sexual.

- Brindar medios de atención al afectado y asegurar su inmediata protección. 
- Garantizar un procedimiento que sobre la base del debido proceso determine responsabilidades y sanciones.

- Realizar la conformación de entes (comité o delegado) que lleve a cabo el procedimiento mencionado.

La OIT considera que el acoso laboral y el hostigamiento sexual siguen siendo un problema mundial que puede afectar a todo tipo de actividad económica, ocupaciones y modalidades de trabajo. Con el objetivo de contribuir a la erradicación de estas conductas, en el año 2019, la OIT adoptó el Convenio 190 (aún no ratificado por el Perú), sobre la violencia y el acoso, y la Recomendación 206 (2019), que tienen como objetivo acabar con este tipo de conductas vejatorias en el mundo del trabajo, otorgando una protección universal frente a estas.

El Convenio 190 de la OIT concibe un concepto integrado de violencia y acoso en el trabajo, y lo define así:

[...] un conjunto de comportamientos y prácticas inaceptables, o de amenazas de tales comportamientos y prácticas, ya sea que se manifiesten una sola vez 0 de manera repetida, que tengan por objeto, que causen, o sean susceptibles de causar, un daño físico, psicológico, sexual o económico, e incluye la violencia y el acoso por razón de género. (Artículo 1)

Así también establece que la expresión "violencia y acoso por razón de género" designa a la violencia y el acoso "dirigidos contra las personas por razón de su sexo o género, o que afectan de manera desproporcionada a personas de un sexo o género determinado, e incluye el acoso sexual" (artículo 1).

Consideramos importante que la OIT no limite la aplicación del Convenio 190 a los trabajadores asalariados, sino que la extienda a todas las personas que trabajan, independientemente de su situación contractual, así como a todo aquel que está en riesgo de sufrir esa violencia o acoso en el trabajo, por ejemplo, los solicitantes de empleo.

\section{IMPACTO DEL COVID-19 EN LAS MUJERES TRABAJADORAS}

Han pasado casi dos años desde que se decretó el estado de emergencia sanitaria y nacional como parte de las medidas adoptadas para mitigar los efectos del COVID-19 por el Gobierno peruano, que determinaron la paralización de diversas actividades económicas, el reinicio gradual y progresivo de algunas de ellas, la aplicación súbita de la educación virtual y el trabajo a distancia (trabajo remoto), la suspensión perfecta de labores, la licencia con goce de haber compensable, nuevas disposiciones en materia de seguridad y salud en el trabajo para la prevención y control de la pandemia en el ámbito laboral, así como otras medidas económico-sociales, como el cierre de fronteras, el aislamiento social obligatorio, la restricción de tránsito, limitación en el aforo 
y distanciamiento social. En este tiempo se ha podido advertir la profundización de las desigualdades preexistentes, que ha impactado en mayor grado y medida en la población femenina.

Las disposiciones establecidas por el Estado, si bien se pueden considerar necesarias en el aspecto sanitario, han traído como consecuencia una grave crisis económica y social que ha impactado en la estabilidad de las empresas, instituciones y hogares; además de la precarización de las condiciones del empleo, que ha significado reducción de jornadas, disminución de las remuneraciones, preferencia por la contratación modal o a tiempo parcial, cierre de centros de trabajo, ceses individuales y colectivos, disminución en la absorción de la nueva mano de obra, entre otros. Esta situación ha devenido en el incremento de los factores de desigualdad que sufren las mujeres en el país, en el entendido de que la situación de violencia estructural que afecta a la mujer trabajadora en el Perú se ha agravado en el contexto de la pandemia del COVID-19.

\section{Discriminación en el empleo: acceso y conservación}

De acuerdo con la diversa evidencia analizada en el documento de investigación Impactos de la epidemia del coronavirus en el trabajo de las mujeres en el Perú (Jaramillo y Ñopo, 2020), existen varios factores por los que se podría inferir que los efectos de la crisis generada por la pandemia podrían afectar a las mujeres de forma desproporcionada, si se considera que las trabajadoras:

[...] se ubican, por lo general, en dos de los sectores potencialmente más golpeados por la crisis (comercio y servicios), [...], mantienen menores tasas de ocupación y están sobrerrepresentadas en el trabajo a tiempo parcial, el autoempleo, la informalidad, el empleo a plazo fijo de menor duración y el empleo en empresas pequeñas, con menor productividad. (p. 9)

El último informe sobre la situación del mercado laboral en Lima Metropolitana del INEI (2020) precisa que durante la pandemia la población ocupada disminuyó en 23,9 \% (1 177500 personas) al compararla con el mismo trimestre móvil durante el año 2019. Además, señala que la tasa de desempleo femenino superó en 1,2 \% a la masculina. Al respecto, si bien esta diferencia se podría apreciar como relativamente estrecha, se la debe contrastar con las variaciones advertidas en la población económicamente activa (PEA) que, si bien indican una caída general, en el caso de las mujeres es 10,7 \% mayor que la de los hombres.

La disminución de la PEA femenina no solo sería la consecuencia de la pérdida de su trabajo, sino que se podría atribuir, como ha sucedido en otros países, a que muchas mujeres habrían postergado la búsqueda de empleo debido al incremento de las responsabilidades familiares y del trabajo en el hogar no remunerado, así como a la precarización de las condiciones laborales. (Cerda et al., 2020, p. 130) 
Sobre el particular, conforme señala la OIT (2020a):

[...] esta crisis ha golpeado con dureza a las mujeres no solo por haber perdido o ver amenazada su fuente laboral, sino por las dificultades que enfrentan para seguir generando ingresos y al mismo tiempo hacerse cargo del trabajo del hogar y el cuidado familiar, en la medida que no cuenten con apoyo necesario y las guarderías y colegios permanezcan cerrados. (p. 16)

\section{Pandemia y violencia doméstica}

En el Perú, la violencia contra las mujeres es un grave problema social que se manifiesta en diversos ámbitos. Esta situación se ha visto agravada exponencialmente durante la cuarentena decretada como mecanismo frente a la pandemia, durante la cual se ha podido visibilizar la persistencia de factores socioculturales que la legitiman.

La violencia doméstica se puede manifestar de diferentes formas: psicológica, sexual, física y económica. Este tipo de violencia, además de afectar gravemente la esfera personal (salud física y mental) y familiar de las mujeres, impacta de forma negativa en su vida laboral, toda vez que es una de las principales causas de ausentismo en el trabajo y ocasiona estrés, bajo rendimiento, daño a las relaciones interpersonales, entre otros, lo cual impacta negativamente en la productividad de las empresas. Al respecto, la OIT (2020b) explica:

El impacto de la violencia doméstica en la salud física y mental de los trabajadores es devastador y, en su expresión más extrema, puede causar la pérdida de vidas. También puede conducir a la dependencia económica de la víctima, lo que puede socavar la capacidad para dejar a una pareja abusiva o para incorporarse al mercado de trabajo y permanecer o progresar en él. (p. 2)

La necesidad de abordar el problema de la violencia doméstica, y las consecuencias que esta genera, determinó que la OIT en el Convenio 190 (2019) exhorte a los "Estados Miembros a reconocer los efectos de la violencia doméstica y tomar medidas para mitigar su impacto". La OIT (2016) también reconoce el rol de los empleadores, quienes "pueden convertirse en aliados frente a esta forma de violencia, aunque no sean responsables de la misma" (p. 44).

Los índices de violencia en nuestro país antes de la pandemia, conforme señalan Jaramillo y Ñopo (2020) citando a la Encuesta Demográfica y de Salud Familiar (Endes) del 2018, reflejan que

2 de cada 3 mujeres reconocen haber sido víctimas de alguna forma de violencia por parte de su pareja. Esta violencia puede ser psicológica o verbal (59\%), física (31\%) o sexual (7\%), pero también algunas mujeres indican haber sido víctimas de una combinación de ellas. (p. 99) 
Estas cifras se habrían visto incrementadas durante la pandemia. Pese a que se considera que el confinamiento habría impedido a muchas víctimas denunciar a sus agresores, el Equipo Itinerante de Urgencia del Ministerio de la Mujer y Poblaciones Vulnerables (MIMP, 2020) ha atendido desde el inicio del estado de emergencia nacional 18778 casos de violencia contra la mujer y el grupo familiar, los cuales se distribuyen de la siguiente manera: violencia física (8564), violencia psicológica (7420), violencia sexual (2741) y violencia económica o patrimonial (53).

La estructura patriarcal en la que se sostiene nuestra sociedad, que genera desigualdad de oportunidades y discriminación para las mujeres, y la situación de vulnerabilidad a la que se encuentran expuestas determinan la urgencia de adoptar políticas públicas que garanticen un sistema de protección social adecuado y eficaz que brinde servicios de prevención de enfermedades mentales o físicas, así como frente a la violencia familiar.

\section{Desigualdad en la asunción de responsabilidades familiares: trabajo doméstico no remunerado}

De acuerdo con el informe Perú, brechas de género 2017. Avances hacia la igualdad de mujeres y hombres (INEI, 2017), antes del inicio de la pandemia, las mujeres dedicaban 39 horas y 28 minutos a la actividad doméstica no remunerada, mientras que los hombres únicamente 15 horas y 54 minutos, lo cual demuestra que existe una brecha de género sobre el uso del tiempo dedicado al trabajo doméstico de 23 horas y 34 minutos. Este problema tiene como origen los estereotipos históricos que atribuyen determinados roles en nuestra sociedad sobre la base del género de las personas.

Las medidas preventivas adoptadas frente al COVID-19 han generado que en los hogares coincidan el cuidado familiar, la realización de trabajo remoto y la educación a distancia. Esta situación ha profundizado las necesidades de atención de los niños, niñas, adolescentes y adultos mayores, tareas que, de acuerdo con el MIMP ${ }^{8}$, se habrían distribuido de forma desigual entre la población femenina y la masculina, pues las horas que dedican las mujeres a labores del hogar no remuneradas se habrían visto incrementadas, debido al desentendimiento de su pareja o al hecho de ser jefa de hogar monoparental.

La asignación desproporcionada de la labor doméstica no remunerada impide que las mujeres se incorporen al mercado laboral formal con condiciones de trabajo óptimas; perjudica sus horarios de trabajo y, por ende, sus remuneraciones; y limita sus oportunidades de crecer profesionalmente. La carga excesiva del cuidado del hogar, además, afecta la distribución del tiempo disponible para otras actividades necesarias e importantes como son el descanso y el ocio.

8 "Encuesta sobre percepciones y aptitudes de mujeres y hombres frente al aislamiento social obligatorio a consecuencia del COVID-19", realizada por el MIMP. 
La desigualdad en el trabajo del hogar no remunerado impacta, directa o indirectamente, en la brecha salarial de géneros, y en los factores negativos en salud física y psicológica. Sin perjuicio de ello, cabe precisar que la labor doméstica "invisible" es un pilar fundamental para el funcionamiento del día a día de la economía formal de la sociedad, por lo que es necesario construir una estructura sólida que permita redistribuir y asignar funciones de trabajo doméstico de forma equitativa.

\section{Brecha digital}

Si bien en los últimos años las tecnologías de la información y la comunicación (TIC), así como las telecomunicaciones, han experimentado un proceso de cambio y exponencial crecimiento en el Perú, otro problema que ha permitido visibilizar la pandemia es la brecha digital y su implicancia en la desigualdad por género. Así, como señalan Jaramillo y Ñopo (2020):

Los hogares de jefatura femenina cuentan con menos acceso a internet, televisión por cable y teléfono celular [...]. La menor conectividad, en un momento clave como este, tiene implicaciones no solo en lo laboral, sino también en la posibilidad de reportar eventuales situaciones de violencia. (pp. 22-23)

La brecha digital es otro factor que impide a las personas desarrollarse en igualdad de condiciones, por lo que la reducción de esta debe ser establecida como una prioridad para el Estado.

\section{Violencia laboral y tecnologías de la información y la comunicación (TIC)}

Finalmente, otro aspecto que se debe considerar en el marco de la pandemia es el incremento de los casos de hostigamiento sexual, que afecta en mayor medida a las mujeres, y de acoso laboral mediante la utilización de las tecnologías de la información y la comunicación (TIC). Esta situación debe ser abordada de manera oportuna por los empleadores a fin de evitar que estas formas de violencia laboral, calificadas como riesgos psicosociales, afecten la integridad y salud de sus trabajadores.

\section{CONCLUSIONES}

1. En el Perú, la violencia contra las mujeres constituye un grave problema arraigado en la sociedad que se manifiesta en diversas formas: violencia psicológica, violencia sexual, violencia física y violencia económica. Esta violencia tiene distintos ámbitos de actuación, como las relaciones laborales, convirtiéndose en conductas muchas veces toleradas, pese a las graves consecuencias que traen para la vida de las mujeres. 
2. La pandemia del COVID-19 supuso una situación negativa para hombres y mujeres en el ámbito personal, familiar y laboral, que se suma a una preexistente y permanente forma de violencia que afecta a dichos ámbitos y que no obedece a una situación circunstancial, como es la emergencia sanitaria, sino a una de carácter estructural.

3. Como hemos podido advertir, tanto en la violencia estructural como frente a los efectos negativos ocasionados por la pandemia, el grupo poblacional más afectado es el femenino.

4. Es necesario adoptar políticas públicas que garanticen de forma efectiva la igualdad de oportunidades para hombres y mujeres basada en términos de justicia, objetividad y razonabilidad; la proscripción de todo acto que contravenga este principio, así como la erradicación de los diversos tipos de violencia que se ejercen contra las mujeres.

\section{REFERENCIAS}

Cerda, R., Domínguez, C., Lafortune, J., Muñoz, N., y Reyes, J. (2020). Empleo femenino y COVID-19: diagnóstico y propuestas. Temas de la Agenda Pública, 15(130), 1-20.

Coloma Cieza, E. (2012). El mobbing, una forma de violencia laboral. Asesoría Laboral, 264, $15-29$.

Convenio 100, Convenio sobre igualdad de remuneración. 29 de junio de 1951. Organización Internacional del Trabajo. https://www.ilo.org/dyn/normlex/es/f?p=NORMLEXP UB:12100:0::NO::P12100_INSTRUMENT_ID:312245

Convenio 111, Convenio sobre la discriminación (empleo y ocupación). 25 de junio de 1958. Organización Internacional del Trabajo. https://www.ilo.org/dyn/normlex/ es/f?p=NORMLEXPUB:12100:0::NO::P12100_ILO_CODE:C111

Convenio 190, Convenio sobre la violencia y el acoso. 10 de junio del 2019. Organización Internacional del Trabajo. https://www.ilo.org/dyn/normlex/es/f?p=NORMLEXP UB:12100:0::NO::P12100_ILO_CODE:C190

Instituto Nacional de Estadística e Informática. (2017). Perú, brechas de género 2017. Avances hacia la igualdad de mujeres y hombres. Edición del Autor.

Instituto Nacional de Estadística e Informática. (2020). Informe técnico sobre la situación del mercado laboral en Lima Metropolitana en el trimestre julio-agosto-septiembre 2020. https://www.inei.gob.pe/media/MenuRecursivo/boletines/10-informetecnico-mercado-laboral-jul-ago-set-2020.pdf 
Jaramillo, M., y Ñopo, H. (2020). Impactos de la epidemia del coronavirus en el trabajo de las mujeres en el Perú [Documento de investigación, 106]. Grupo de Análisis para el Desarrollo (GRADE).

Ministerio de la Mujer y Poblaciones Vulnerables. (2020). Estadísticas del MIMP. https://www.mimp.gob.pe/omep/estadisticas-violencia.php\#: :text=Los\%20 Equipos\%20ltinerantes\%20de\%20Urgencia,feminicidios\%20y\%20tentativa\%20 de\%20feminicidios

Ministerio de Trabajo y Promoción del Empleo. (2019). Resumen del Informe Anual del Empleo. https://cdn.www.gob.pe/uploads/document/file/1014704/IAE_2020_ propuesta_V4.pdf

Organización Internacional del Trabajo. (2008). El ABC de los derechos de las trabajadoras

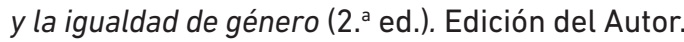

Organización Internacional del Trabajo. (6-3 de octubre del 2016). Informe final de la Reunión de expertos sobre la violencia contra las mujeres y los hombres en el mundo del trabajo. https://www.ilo.org/wcmsp5/groups/public/---ed_norm/--relconf/documents/meetingdocument/wcms_546113.pdf

Organización Internacional del Trabajo. (2017). Trabajo Decente y la Agenda 2030 de Desarrollo Sostenible. https://www.ilo.org/wcmsp5/groups/public/--dgreports/---dcomm/documents/publication/wcms_470340.pdf

Organización Internacional del Trabajo. (2020a). Impacto COVID-19 en América Latina y el Caribe. Análisis y recomendaciones para incidir en políticas públicas y privadas, con enfoque de género. https://www.ilo.org/wcmsp5/groups/public/---americas/--ro-lima/documents/publication/wcms_763188.pdf

Organización Internacional del Trabajo. (2 de abril del 2020b). La violencia doméstica y su impacto en el mundo del trabajo. Servicio de Género, Igualdad y Diversidad; OITSIDA, Departamento de Condiciones de Trabajo e Igualdad. https://www.ilo. org/wcmsp5/groups/public/---dgreports/---gender/documents/briefingnote/ wcms_740544.pdf

Organización Internacional del Trabajo. (2020c). The COVID-19 Response: Getting Gender Equality Right for a Better Future for Women at Work. https://www.ilo.org/wcmsp5/ groups/public/---dgreports/---gender/documents/publication/wcms_744374. pdf

Organización Internacional del Trabajo. (s. f.). Misión e impacto de la OIT. Recuperado el 12 de noviembre del 2021 de https://www.ilo.org/global/about-the-ilo/missionand-objectives/lang--es/index.htm 
Pacto Internacional de Derechos Civiles y Políticos. Adoptado y abierto a la firma, ratificación y adhesión por la Asamblea General en su resolución 2200 A (XXI). 16 de diciembre de 1966. https://www.ohchr.org/Documents/Professionallnterest/ ccpr_SP.pdf

Pacto Internacional de Derechos Económicos, Sociales y Culturales. Adoptado y abierto a la firma, ratificación y adhesión por la Asamblea General en su resolución 2200 A (XXI). 16 de diciembre de 1966. https://www.ohchr.org/Documents/ Professionallnterest/cescr_SP.pdf 
